\title{
Outcomes of Extracorporeal Life Support in Trauma
}

\author{
Keywords: Trauma; Extraconoreal life support; ECLS; ECMO

\section{Abstract} \\ Background: Extracomoreal life support (ECLS) is a life- \\ saving treatment for critically ill trauma patients with refractory \\ cardiopulmonary failure. The purpose of this analysis is to use a large \\ national trauma database to characterize the use and outcomes of \\ ECLS in trauma.
}

Methods: Patients from centers that performed ECLS were identified from the 2007-2009 National Trauma Data Bank (NTDB). Demographic, clinical, and outcome data were abstracted. Univariate analyses were performed using chi-square, Mann-Whitney $\mathrm{U}$-test, and regression analyses. Propensity score analysis and multiple regression models were developed using backwards stepwise logistic regression to identify risk factors for ECLS and predictors of mortality: $p<0.05$ was considered significant.

Results: Forty-two centers of $682(6 \%)$ performed ECLS on 78 of 245,950 patients $(0.03 \%)$. ECLS patients were younger, more severely injured, had a longer ICU and hospital length of stay, and a higher mortality. Univariate analysis showed that ECLS patients had a significantly increased risk of death (OR 28;95\% Cl 18-43; $p<0.001$ ). Among patients receiving ECLS, predictors of mortality included injury severity score (ISS) (OR 1.06; $95 \% \mathrm{Cl} 1.01-1.11 ; \mathrm{p}=0.03$ ) and cardiac arrest (OR 7.57; $95 \% \mathrm{Cl} 1.58-36.2 ; \mathrm{p}=0.01$ ). After propensity score adjusted logistic regression, ECLS was still a significant predictor of mortality (OR 6, 95\% Cl 2.76-13.1, p<0.01). Patients receiving ECLS at a center that performed 5 or more ECLS runs trended towards a lower mortality rate $(27 \%$ vs. $73 \%, p=0.10)$

Conclusions: ECLS is infrequently used in the trauma setting. When compared to other trauma patients, ECLS patients are more critically ill and are at increased odds of death. Further study is required to determine which patient and hospital characteristic spredict improved survival.

\section{Introduction}

The role of extracorporeal life support (ECLS) in the management of acute respiratory failure of the trauma victim is not well defined. Several case reports and small case series describe the use of ECLS in the management of pediatric and adult traumatic respiratory failure including blunt and penetrating parenchymal and tracheobronchial injuries [1-10], cardiac contusions [11-13], traumatic brain injury [14-17], and shock [18-20]. Retrospective cohort studies of trauma patients cared for at tertiary care referral centers report survival after ECLS ranging from $50-79 \%$ [21-24]. These case reports, small case series, and retrospective reviews suggest a potential role for ECLS in the management of traumatically injured patients.

The National Trauma Data Bank collects and maintains a large, detailed registry of de-identified trauma data voluntarily submitted from participating trauma centers. The purpose of this analysis is to use a large national trauma database to characterize the use and outcomes of ECLS in trauma patients.

\section{Methods}

This study was approved by The University of Texas Health Science Center Institutional Review Board (IRB\# HSC-MS-10-0215).

\section{Journal of Surgery}

Debbie F. Lew ${ }^{1}$, Curtis J. Wray ${ }^{1}$, Kevin P. Lally ${ }^{1}$, Lillian S. $\mathrm{KaO}^{1}$ and Adam M. Vogel ${ }^{2 *}$

${ }^{1}$ University of Texas Health Science Center at Houston, Houston, Texas, USA

${ }^{2}$ Division of Pediatric Surgery, Washington University School in St. Louis School of Medicine, St. Louis, Missouri, USA

\section{*Address for Correspondence}

Adam M. Vogel, MD, Assistant Professor, Division of Pediatric Surgery, Washington University in St. Louis School of Medicine, St. Louis Children's Hospital, One Children's Place, Suite 5S40, St. Louis, MO 63110, USA, Tel: (314) 454-6022; Fax: (314) 454-2442; E-mail: vogelam@wudosis.wustl.edu

Copyright: (c) 2014 Lew DF, et al. This is an open access article distributed under the Creative Commons Attribution License, which permits unrestricted use, distribution, and reproduction in any medium, provided the original work is properly cited.

Submission: 09 December 2014

Accepted: 15 December 2014

Published: 20 December 2014

Reviewed \& Approved by: Dr. Michael Leitman, Professor of Surgery, Icahn School of Medicine at Mount Sinai, USA

The National Trauma Data Bank (NTDB) is a large aggregation of United States trauma registry data administered by the American College of Surgeons. Patients from centers that performed ECLS were identified from the 2007-2009 NTDB using the procedure code 36822 (insertion of cannulas for ECLS). Patients were divided into those who received ECLS and those who did not. Demographic, clinical, and outcome data were abstracted including: age, gender, ethnicity, injury severity score, injury mechanism, physiologic variables on admission, Glasgow Coma Score (GCS), comorbidities, complications, and mortality. Descriptive analyses were performed using chi-square tests, and student's t-test or Mann-Whitney U-tests. Univariate analyses were used to identify predictors of mortality at a p-value $<0.20$. A multivariate logistic regression model was developed using backwards-stepwise elimination. P-values less than or equal to 0.05 were considered significant.

Since patients were not randomized in this study, propensity score matching was performed to reduce selection bias [25]. Propensity scores representing the estimated probabilities of patients receiving ECLS were developed from a multivariate logistic regression model with ECLS therapy as the binary dependent variable. All measured covariates that could be related to ECLS use were included as predictor variables. Overlap between treatment and control group was estimated using histograms. Based upon the score, each patient who received ECLS was matched to control patients who did not receive ECLS. A 4-to-1 matching process was utilized to match controls to cases. Covariates that increased the bias between treatment and control were not included in the model. The final propensity score adjusted multivariate logistic regression model was used to compare the mortality between ECLS patients and matched controls.

\section{Results}

Forty-two out of 682 centers (6\%) performed ECLS on 78 of 245,950 patients (0.03\%). Only 3 of the 42 ECLS sites performed 5 or more runs of ECLS, and only one site performed more than 10 runs. Table 1 shows patient demographics, clinical characteristics including comorbidities, and outcome measures. In general, ECLS patients were younger and more severely injured. ECLS and nonECLS patients had similar comorbidities. ECLS patients had a 
Table 1: Patient Demographics, Clinical Characteristics, and Outcome.

Univariate analyses of patients who did and did not receive extracorporeal life support (ECLS) using chi-square and Mann-Whitney U-tests.

\begin{tabular}{|c|c|c|c|}
\hline & $\begin{array}{l}\text { ECLS } \\
(n=78)\end{array}$ & $\begin{array}{c}\text { No-ECLS } \\
(n=245,872)\end{array}$ & $p$ \\
\hline Median Age, years (IQR) & $23(16-37)$ & $39(23-57)$ & $<0.001$ \\
\hline Median SBP, mmHg (IQR) & $116(92-140)$ & $98(81-116)$ & $<0.001$ \\
\hline Median Pulse, bpm (IQR) & $114(80-137)$ & $98(81-116)$ & $<0.001$ \\
\hline Female (\%) & $21(27)$ & $79242(32)$ & 0.43 \\
\hline \multicolumn{4}{|l|}{ Mechanism } \\
\hline Blunt (\%) & $41(53)$ & $176075(72)$ & $<.001$ \\
\hline Penetrating (\%) & $9(12)$ & $25878(11)$ & 0.77 \\
\hline Burn (\%) & $12(15)$ & $7827(3)$ & $<.001$ \\
\hline Other/Unknown (\%) & $16(21)$ & $37069(15)$ & 0.15 \\
\hline \multicolumn{4}{|l|}{ Comorbidities } \\
\hline Alcoholism (\%) & $11(14)$ & $15227(6)$ & 0.004 \\
\hline Ascites w/in 30 days (\%) & $2(3)$ & $164(<1)$ & $<0.001$ \\
\hline Bleeding disorder (\%) & $3(4)$ & $4131(2)$ & 0.14 \\
\hline Congestive heart failure (\%) & $2(3)$ & $3834(2)$ & 0.47 \\
\hline CVA/residual neurological defect (\%) & $2(3)$ & $3304(1)$ & 0.35 \\
\hline Diabetes mellitus (\%) & $2(3)$ & $13406(6)$ & 0.26 \\
\hline Hypertension requiring medication (\%) & $5(6)$ & $34452(14)$ & 0.05 \\
\hline Impaired sensorium (\%) & $7(9)$ & $10623(4)$ & 0.04 \\
\hline Pre-injury dialysis (\%) & $2(3)$ & $693(<1)$ & $<0.001$ \\
\hline Median LOS, days (IQR) & $20(6-36)$ & $12(5-23)$ & $<0.001$ \\
\hline Median ICU LOS, days (IQR) & $17(5-28)$ & $5(2-13)$ & $<0.001$ \\
\hline Median Ventilator days (IQR) & $12(5-24)$ & $3(1-9)$ & $<0.001$ \\
\hline Mortality (\%) & $40(51)$ & $8959(4)$ & $<0.001$ \\
\hline
\end{tabular}

*IQR: Interquartile Range; ISS: Injury Severity Score; GCS: Glasgow Coma Score; bpm: beats per minute; LOS: Length of Stay; ICU: Intensive Care Unit.

longer intensive care unit (ICU) and hospital length of stay and were considered more likely to die. Patients receiving ECLS at a center that performed 5 or more ECLS runs had a lower mortality rate, although the difference was not statistically significant ( $27 \%$ vs. $73 \%, p=0.10)$. Univariate analysis showed that ECLS patients had a significantly increased odds of death (OR 28; CI 18-43; $p<0.001)$. In patients that received ECLS, injury severity score (OR 1.06; CI 1.02-1.11; $p=0.027)$ and cardiac arrest (OR 7.57; CI 1.58-36.2, $p=0.011$ ) were independent predictors of mortality on logistic regression analysis.

There was sufficient overlap in propensity scores to match 53 ECLS patients to 212 controls. Following propensity score matching, there were no significant differences between patients who received ECLS and those that did not with respect to patient demographics and clinical characteristics (Table 2). There were also no differences found between the matched groups with regard to complications. However, mortality amongst patients receiving ECLS remained higher (50\% vs. $31 \%, p=0.01)$. The propensity score adjusted multivariate logistic regression identified ECLS use, injury severity score, age, systolic blood pressure and GCS on admission as independent predictors of mortality (Table 3).

\section{Discussion}

Review of the National Trauma Data Bank shows that the utilization of ECLS in the management of critically ill trauma patients is rare. Not surprisingly, patients that receive ECLS are more critically ill and are at increased risk of complications and death. However, ECLS has become a powerful tool for managing acute cardiorespiratory failure in critically ill patients. Significant advances in critical care such as advanced lung protection strategies along with major advances in extracorporeal technology (catheters, oxygenator, heparin bonded circuitry, improvements in pump design, etc.) have led to a surge in the use of ECLS for the management of adult cardiorespiratory failure. In 2009, the results of a randomized, prospective trial of ECLS in critically ill adult patients with acute respiratory failure 
Table 2: Difference between groups after propensity score matching

Propensity score matched ECLS and no-ECLS patients were compared using student's t-test. Patient characteristics and complications were similar between groups

\begin{tabular}{|c|c|c|c|}
\hline Variable & $\begin{array}{l}\text { ECLS } \\
(n=53)\end{array}$ & $\begin{array}{l}\text { No ECLS } \\
(n=212)\end{array}$ & $\mathbf{P}$ \\
\hline Mean Age (years) & 27.5 & 29.5 & 0.59 \\
\hline Mean ISS & 25.9 & 27.1 & 0.67 \\
\hline Mean SBP (mmHg) & 117 & 119 & 0.86 \\
\hline Mean Pulse & 112 & 115 & 0.56 \\
\hline Mean GCS Total & 9.7 & 9.6 & 0.95 \\
\hline Mortality (\%) & 50 & 31 & 0.01 \\
\hline Mean ICU LOS, days & 23 & 23 & 0.91 \\
\hline \multicolumn{4}{|l|}{ Comorbidities } \\
\hline Respiratory failure (\%) & 13 & 15 & 0.78 \\
\hline Alcoholism (\%) & 15 & 17 & 0.79 \\
\hline Ascites in 30 days (\%) & 2 & 1 & 0.68 \\
\hline $\begin{array}{l}\text { Hypertension requiring } \\
\text { medication (\%) }\end{array}$ & 9 & 12 & 0.64 \\
\hline Impaired sensorium (\%) & 6 & 9 & 0.52 \\
\hline Bleeding disorder (\%) & 11 & 11 & 0.94 \\
\hline \multicolumn{4}{|l|}{ Complications } \\
\hline $\begin{array}{l}\text { Abdominal compartment } \\
\text { syndrome (\%) }\end{array}$ & 4 & 2 & 0.68 \\
\hline $\begin{array}{l}\text { Abdominal fascia left } \\
\text { open }\end{array}$ & 6 & 4 & 0.74 \\
\hline Acute renal failure & 34 & 34 & 0.96 \\
\hline $\begin{array}{l}\text { Acute respiratory distress } \\
\text { syndrome }\end{array}$ & 45 & 50 & 0.60 \\
\hline Base deficit & 13 & 16 & 0.68 \\
\hline Bleeding & 11 & 11 & 0.94 \\
\hline $\begin{array}{l}\text { Cardiac arrest with } \\
\text { cardiopulmonary } \\
\text { resuscitation }\end{array}$ & 25 & 25 & 1.00 \\
\hline Coagulopathy & 15 & 12 & 0.68 \\
\hline $\begin{array}{l}\text { Deep vein thrombosis / } \\
\text { thrombophlebitis }\end{array}$ & 4 & 3 & 0.79 \\
\hline Myocardial infarction & 4 & 4 & 1.00 \\
\hline Pneumonia & 21 & 25 & 0.61 \\
\hline Pulmonary embolism & 8 & 4 & 0.48 \\
\hline $\begin{array}{l}\text { Stroke/cerebrovascular } \\
\text { accident }\end{array}$ & 4 & 1 & 0.45 \\
\hline Systemic sepsis & 11 & 14 & 0.67 \\
\hline Unplanned intubation & 8 & 9 & 0.73 \\
\hline
\end{tabular}

(Conventional ventilatory support versus extracorporeal membrane oxygenation for Severe Adult Respiratory failure; CESAR) were published. This trial showed improved outcome in those patients who were managed at an ECLS center [26]. This trial only enrolled a small proportion (12/180 or $7 \%$ ) of trauma patients, which included patients undergoing surgery. Nonetheless, given these results, the use of ECLS has become more widely utilized in critically ill patients with cardiopulmonary failure of various etiologies, including those with traumatic injuries.
Several case reports and small case series illustrate the utility of ECLS in carefully selected traumatically injured patients. With respect to blunt and penetrating thoracic trauma, venoarterial (VA) ECLS has been successfully used in managing postoperative cardiopulmonary failure following pneumonectomy for penetrating thoracic trauma [27]. Both venovenous (VV) and VA ECLS have been employed for perioperative management of patients who sustained traumatic tracheobronchial rupture to enable successful operative repair $[3,8,13]$. VV ECLS has been used in several patients to manage respiratory failure from extensive traumatic pulmonary contusion and hemorrhage $[1,2,6,13,28]$. VA ECLS has also been successfully employed in the management of cardiac failure from traumatic cardiac contusion and hemorrhagic shock $[11,12,18,20]$.

Several experienced ECLS centers have retrospectively reported their single center experience with traumatically injured patients. The University of Michigan reviewed 30 adult trauma patients who received ECLS between 1989 and 1997 [21]. Their patients had an average age of 26 years, were $50 \%$ male and had predominately blunt mechanism of injury. The survival to discharge in this cohort was $50 \%$. They found that fewer days of pre-ECLS ventilation and more normal venous oxygen saturation were associated with survival. Acute renal failure and the need for venoarterial support were more common in those who died. Bleeding complications were common (59\%) but not associated with mortality. Early implementation of ECLS was associated with increased odds of survival. The United Kingdom experience was described in a single center retrospective review of 28 patients from 1992 to 2000 [22]. The predominant mechanism was blunt road traffic crashes with multisystem traumatic injury. Direct pulmonary contusion and fat-emboli were common contributing factors to refractory acute respiratory failure and the need for ECLS. Overall, $71 \%$ of patients were successfully weaned from ECLS support. Patient age, duration of ECLS, and duration of pre-ECLS ventilator support did not differ between survivors and non-survivors. Patients with lower ISS and isolated long bone fractures had a worse outcome on ECLS, perhaps illustrating different physiologic recovery from fat emboli syndrome when compared to other etiologies of acute respiratory failure. More recently, a retrospective analysis of

Table 3: Predictors of mortality following propensity score matching. Multivariate logistic regression analysis of ECLS and propensity score matched no-ECLS patients.

\begin{tabular}{|l|c|c|c|}
\hline & OR & $95 \%$ Cl & $p$-value \\
\hline Use of ECLS & 6.00 & $2.76-13.1$ & $<.001$ \\
\hline Alcoholism & 0.47 & $0.41-0.54$ & $<.001$ \\
\hline Ascites within 30 days & 2.29 & $1.04-5.04$ & 0.04 \\
\hline Injury severity score (ISS) & 1.05 & $1.05-1.05$ & $<.001$ \\
\hline Age & 1.05 & $1.04-1.04$ & $<.001$ \\
\hline Systolic blood pressure & 1.00 & $1.00-1.00$ & $<.001$ \\
\hline Total GCS & 0.90 & $0.89-0.90$ & $<.001$ \\
\hline Mechanism (Ref: Blunt) & & & $<.001$ \\
\hline Burn & 2.69 & $2.22-3.25$ & $<.001$ \\
\hline Penetrating & 1.80 & $1.59-2.03$ & $<.001$ \\
\hline Other & 2.85 & $2.43-3.34$ & 0.06 \\
\hline Unknown & 1.13 & $1.00-1.29$ & $<$ \\
\hline
\end{tabular}


prospectively collected, single center, registry data of 52 consecutive trauma patients receiving ECLS from 2002 through 2012 for posttraumatic respiratory failure was conducted [24]. Like previous studies, the predominant mechanism was automobile crash $(73 \%)$ and the patients were severely injured with a mean ISS of $58.9 \pm 10.5$ and a mean lung injury score of $3.3 \pm 0.6$. Their series is notable for utilizing both pump-less and pump-driven ECLS, 98\% percutaneous cannulation, and minimal complications. Their overall survival was $79 \%$ and compares favorably to the proposed ISS-related mortality of $59 \%$. These studies conclude that ECLS is feasible in the critically ill, traumatically injured population and may have a role for patients who develop severe respiratory distress associated with trauma.

Our current study provides a snapshot of the number of centers in the Unites States that provide the option of ECLS in the management of their severely injured trauma population and their outcomes. The mortality of $51 \%$ is comparable to the mortality seen in other studies. Patients at these centers that received ECLS as part of their clinical course were more critically ill and would be expected to have an increased odds of poor outcome. Not surprisingly, predictors of mortality using propensity score matching showed that receiving ECLS, as well as injury severity and physiological derangement were related to increased odds of death. The data suggests that less injured, critically ill trauma patients are more likely to benefit from ECLS.

There are several limitations to this study that may impact the results and conclusions. Due to the nature of the NTDB, the true primary indication for ECLS is unknown. The dataset does not enable analysis of the timing of ECLS and the temporal relationship of various complications in clinical outcome. Second, there may be additional unmeasured confounders; traditional regression analyses and propensity score analyses can only account for observed confounders. Thus, ECLS patients may have been more critically ill than non-ECLS patients, even after propensity score matching. However, the reduction in the odds ratio for the association between ECLS and mortality from 28 to 6 after propensity score matching suggests a reduction in selection bias with this statistical method. Lastly, the lack of pertinent clinical data such as clinical physiologic variables, mechanical ventilation parameters, cardiac function, and renal function makes it difficult to clinically apply these results.

Like many aspects of critical care, providing ECLS requires multidisciplinary coordination across many medical, nursing, and respiratory therapy subspecialties. The design, implementation, maintenance, and experience of ECLS teams are important to delivering the highest quality of ECLS care. In this context, hospital experience and regional ECLS referral patterns may play a role in outcome $[29,30]$. As with most complex technologies and procedures, increased experience, over time, should improve outcome and this trend is observed in this study. Unfortunately, this type of data is also unavailable from the NTDB but might be reflected in the fact that survival was improved in sites that performed more ECLS runs.

As with most papers, this study generates more questions than answers. Further investigation is required to identify which patients are most likely to benefit from ECLS, the optimal management (sedation and analgesia, mechanical ventilator "rest" settings, nutrition, systemic anticoagulation, etc.) of trauma patients on ECLS, the role of specialized trauma centers for ECLS, and the metrics by which these centers should be judged. This issue is partially addressed in this study but a more complete and robust clinical data set and analysis is required to provide more definitive conclusions, particularly with respect to timing of potential transfer or initiating ECLS. However, the success documented in this review, multiple case reports, case series, and small retrospective reviews suggest an important role of ECLS in the management of critically ill trauma patients and that these are questions worth answering. Additional investigations and trials are needed to determine which patient and hospital characteristics will allow for optimal utilization of this resource-intensive intervention to achieve maximal benefit in critically injured trauma victims.

\section{References}

1. Liao $\mathrm{CH}$, Huang YK, Tseng CN, Wu MY, Tsai FC (2008) Successful use of extracorporeal life support to resuscitate traumatic inoperable pulmonary hemorrhage. J Trauma 64: E15-E17.

2. Yuan KC, Fang JF, Chen MF (2008) Treatment of endobronchial hemorrhage after blunt chest trauma with extracorporeal membrane oxygenation (ECMO). J Trauma 65: 1151-1154.

3. Madershahian N, Wittwer T, Strauch J, Franke UF, Wippermann J, et al. (2007) Application of ECMO in multitrauma patients with ARDS as rescue therapy. J Card Surg 22: 180-184.

4. Brederlau J, Anetseder M, Schoefinius A, Wurmb T, Muellenbach R, et al. (2008) Arteriovenous extracorporeal lung assist and high frequency oscillatory ventilation in post-traumatic acute respiratory distress syndrome. $\mathrm{J}$ Trauma 64: E65-E68.

5. Brederlau J, Anetseder M, Wagner R, Roesner T, Philipp A, et al. (2004) Pumpless extracorporeal lung assist in severe blunt chest trauma. J Cardiothorac Vasc Anesth 18: 777-779.

6. Schupp M, Swanevelder JL, Peek GJ, Sosnowski AW, Spyt TJ (2003) Postoperative extracorporeal membrane oxygenation for severe intraoperative SIRS $10 \mathrm{~h}$ after multiple trauma. Br J Anaesth 90: 91-94.

7. Fortenberry JD, Meier AH, Pettignano R, Heard M, Chambliss CR, et al. (2003) Extracorporeal life support for posttraumatic acute respiratory distress syndrome at a children's medical center. J Pediatr Surg 38: 1221-1226.

8. Campione A, Agostini M, Portolan M, Alloisio A, Fino C, et al. (2007) Extracorporeal membrane oxygenation in respiratory failure for pulmonary contusion and bronchial disruption after trauma. J Thorac Cardiovasc Surg 133: 1673-1674.

9. Zimmermann M, Philipp A, Schmid FX, Dorlac W, Arlt M, et al. (2007) From Baghdad to Germany: use of a new pumpless extracorporeal lung assist system in two severely injured US soldiers. ASAIO J 53: e4-e6.

10. McKinlay J, Chapman G, Elliot S, Mallick A (2008) Pre-emptive Novalungassisted carbon dioxide removal in a patient with chest, head and abdominal injury. Anaesthesia 63: 767-770.

11. DeBerry BB, Lynch JE, Chernin JM, Zwischenberger JB, Chung DH (2007) Successful management of pediatric cardiac contusion with extracorporeal membrane oxygenation. J Trauma 63: 1380-1382.

12. Masiakos PT, Hirsch EF, Millham FH (2003) Management of severe combined pulmonary and myocardial contusion with extracorporeal membrane oxygenation. J Trauma 54: 1012-1015.

13. Voelckel W, Wenzel V, Rieger M, Antretter H, Padosch S, et al. (1998) Temporary extracorporeal membrane oxygenation in the treatment of acute traumatic lung injury. Can J Anaesth 45: 1097-1102.

14. Skarda D, Henricksen JW, Rollins M (2012) Extracorporeal membrane oxygenation promotes survival in children with trauma related respiratory failure. Pediatr Surg Int 28: 711-714.

15. Yen TS, Liau CC, Chen YS, Chao A (2008) Extracorporeal membrane oxygenation resuscitation for traumatic brain injury after decompressive craniotomy. Clin Neurol Neurosurg 110: 295-297. 
16. Frickey N, Kraincuk P, Zhilla I, Binder T, Plochl W (2008) Fulminant pulmonary embolism treated by extracorporeal membrane oxygenation in a patient with traumatic brain injury. J Trauma 64: E41-E43.

17. Friesenecker BE, Peer R, Rieder J, Lirk P, Knotzer H, et al. (2005) Craniotomy during ECMO in a severely traumatized patient. Acta Neurochir (Wien) 147 993-996.

18. Arlt M, Philipp A, Voelkel S, Rupprecht L, Mueller T, et al. (2010) Extracorporea membrane oxygenation in severe trauma patients with bleeding shock. Resuscitation 81: 804-809.

19. Perchinsky MJ, Long WB, Hill JG, Parsons JA, Bennett JB (1995) Extracorporeal cardiopulmonary life support with heparin-bonded circuitry in the resuscitation of massively injured trauma patients. Am J Surg 169: 488491.

20. Sasadeusz KJ, Long WB 3rd, Kemalyan N, Datena SJ, Hill JG (2000) Successful treatment of a patient with multiple injuries using extracorporeal membrane oxygenation and inhaled nitric oxide. J Trauma 49: 1126-1128.

21. Michaels AJ, Schriener RJ, Kolla S, Awad SS, Rich PB, et al. (1999) Extracorporeal life support in pulmonary failure after trauma. J Trauma 46 638-645.

22. Cordell-Smith JA, Roberts N, Peek GJ, Firmin RK (2006) Traumatic lung injury treated by extracorporeal membrane oxygenation (ECMO). Injury 37 29-32.

23. Bonacchi M, Spina R, Torracchi L, Harmelin G, Sani G, et al. (2013) Extracorporeal life support in patients with severe trauma: an advanced treatment strategy for refractory clinical settings. J Thorac Cardiovasc Surg 145: $1617-1626$
24. Ried M, Bein T, Philipp A, Mueller T, Graf B, et al. (2013) Extracorporeal lung support in trauma patients with severe chest injury and acute lung failure: a 10-year institutional experience. Crit Care 17: R110.

25. Rosensaum PR, Rubin DB (1983) The central role of the propensity score in observational studies for causal effects. Biometrika 70: 41-55.

26. Peek GJ, Mugford M, Tiruvoipati R, Wilson A, Allen E, et al. (2009) Efficacy and economic assessment of conventional ventilatory support versus extracorporeal membrane oxygenation for severe adult respiratory failure (CESAR): a multicentre randomised controlled trial. Lancet 374: 1351-1363.

27. Rosenthal A, McKenney M, Sanchez R, Lee S, Carrillo EH (2009) Extracorporeal membrane oxygenation for severe hypoxemia after trauma pneumonectomy. Am Surg 75: 1258-1260.

28. Masroor S, Tehrani H, Pham S, Neijman T, Martinez-Ruiz R, et al. (2004) Extracorporeal life support in pulmonary failure after traumatic rupture of the thoracic aorta: a case report. J Trauma 57: 389-391.

29. Michaels AJ, Hill JG, Long WB, Young BP, Sperley BP, et al. (2013) Adult refractory hypoxemic acute respiratory distress syndrome treated with extracorporeal membrane oxygenation: the role of a regional referral center. Am J Surg 205: 492-498.

30. Mullany DV, Bull TN, Hunt W, Shekar K, Thomson B, et al. (2012) Outcomes of the first 30 cases of an adult extracorporeal membrane oxygenation program: strategies to manage the "learning curve" and implications for intensive care unit risk adjustment models. Crit Care Resusc 14: 119-129.

\section{Acknowledgements}

The authors wish to acknowledge Mrs. Susan Phillips for her critical appraisal of the manuscript. 